\title{
Weight gain prevention among black women in the rural community health center setting: The Shape Program
}

Perry Foley ${ }^{1 *}$, Erica Levine ${ }^{1}$, Sandy Askew ${ }^{1}$, Elaine Puleo ${ }^{2}$, Jessica Whiteley ${ }^{3}$, Bryan Batch $^{4}$, Daniel Heil ${ }^{5}$, Daniel Dix ${ }^{1}$, Veronica Lett ${ }^{1}$, Michele Lanpher ${ }^{1}$, Jade Miller ${ }^{1}$, Karen Emmons ${ }^{6}$ and Gary Bennett ${ }^{1}$

\begin{abstract}
Background: Nearly $60 \%$ of black women are obese. Despite their increased risk of obesity and associated chronic diseases, black women have been underrepresented in clinical trials of weight loss interventions, particularly those conducted in the primary care setting. Further, existing obesity treatments are less effective for this population. The promotion of weight maintenance can be achieved at lower treatment intensity than can weight loss and holds promise in reducing obesity-associated chronic disease risk. Weight gain prevention may also be more consistent with the obesity-related sociocultural perspectives of black women than are traditional weight loss approaches.
\end{abstract}

Methods/Design: We conducted an 18-month randomized controlled trial (the Shape Program) of a weight gain prevention intervention for overweight black female patients in the primary care setting. Participants include 194 premenopausal black women aged 25 to 44 years with a BMI of $25-34.9 \mathrm{~kg} / \mathrm{m}^{2}$. Participants were randomized either to usual care or to a 12-month intervention that consisted of: tailored obesogenic behavior change goals, self-monitoring via interactive voice response phone calls, tailored skills training materials, 12 counseling calls with a registered dietitian and a 12-month YMCA membership.

Participants are followed over 18 months, with study visits at baseline, 6-, 12- and 18-months. Anthropometric data, blood pressure, fasting lipids, fasting glucose, and self-administered surveys are collected at each visit.

Accelerometer data is collected at baseline and 12-months.

At baseline, participants were an average of 35.4 years old with a mean body mass index of $30.2 \mathrm{~kg} / \mathrm{m}^{2}$. Participants were mostly employed and low-income. Almost half of the sample reported a diagnosis of hypertension or prehypertension and 12\% reported a diagnosis of diabetes or prediabetes. Almost one-third of participants smoked and over 20\% scored above the clinical threshold for depression.

Discussion: The Shape Program utilizes an innovative intervention approach to lower the risk of obesity and obesity-associated chronic disease among black women in the primary care setting. The intervention was informed by behavior change theory and aims to prevent weight gain using inexpensive mobile technologies and existing health center resources. Baseline characteristics reflect a socioeconomically disadvantaged, high-risk population sample in need of evidence-based treatment strategies.

Trial registration: The trial is registered with clinicaltrials.gov NCT00938535.

Keywords: Obesity, Weight, eHealth, Women's health, Minority health, Primary care, Prevention

\footnotetext{
*Correspondence: perry.foley@duke.edu

'Duke Obesity Prevention Program, Duke Global Health Institute, 2812 Erwin

Road, Suite 403 Box 90392, Durham, NC 27705, USA

Full list of author information is available at the end of the article
} 


\section{Background}

The epidemic of obesity in the U.S. shows no signs of abating - presently, almost $70 \%$ of the adult U.S. population is either overweight or obese [1]. Black women are disproportionately affected by the condition. Between 1976 and 2008, obesity among black women increased more than $60 \%[2,3]$. Nearly $60 \%$ of black women are obese, a rate that is twice that of non-Hispanic white women [1]. Socioeconomic status and obesity are less strongly associated in black women than in other groups. Nevertheless, socioeconomic factors strongly pattern exposure to obesogenic environmental factors $[4,5]$, the adoption of obesogenic risk behaviors [6], the limited availability of weight management resources $[7,8]$, and the efficacy of obesity treatment strategies in the primary care setting [9].

Despite their vastly increased risk of obesity and associated chronic disease $[10,11]$, racial/ethnic minority and socioeconomically disadvantaged populations have been underrepresented in clinical trials of weight loss interventions [11]. This is problematic because promoting weight loss among black women is a longstanding and vexing clinical challenge [12,13]. Evidencebased obesity treatments are consistently less effective and absolute weight losses are generally smaller among black women, compared to other populations $[10,11,14]$. There is growing recognition that alternative clinical treatment strategies are necessary to contend with the challenge of obesity [14-17]. While it is undeniable that weight loss is the optimal treatment strategy for many obese individuals, weight gain prevention may have considerable clinical utility among overweight and some obese black women.

Weight gain prevention holds promise in reducing risk associated with cardiovascular diseases (CVD), type 2 diabetes, some cancers [18] and perhaps premature mortality [19]. Weight gain prevention may have particular benefits for blacks, who exhibit disproportionately greater rates of adulthood weight gain $[20,21]$ and extreme obesity [2], both of which increase obesityassociated chronic disease risk [22-24]. Relative to whites, black women have weaker associations of adiposity with cardiovascular risk factors [25-28] and mortality from cardiovascular disease $[29,30]$ and all causes. Thus, promoting weight stability within the overweight $\left(\mathrm{BMI}=25-29.9 \mathrm{~kg} / \mathrm{m}^{2}\right)$ and lower levels of the Class 1 obesity ranges $\left(B M I=30-34.9 \mathrm{~kg} / \mathrm{m}^{2}\right)$ might be an appropriate chronic disease risk reduction strategy in black women, especially prior to menopause, when weight gains are particularly pronounced [31,32].

Additionally, we suspect that weight gain prevention strategies may be more consistent with the sociocultural experiences of black women, compared to traditional weight loss approaches. While some opposing data exist, most studies have shown that black women are more tolerant of heavier body weights, as compared to white women [33]. Blacks have a greater social acceptance of overweight, less body weight dissatisfaction, and higher body weight ideals than do whites [12,33-40]. A number of studies have shown that overweight blacks are less likely to perceive themselves to be overweight, compared to whites and Hispanics [41-43]. Perceived body image and attractiveness are not as strongly linked with weight in black women, compared to white women. Moreover, a majority of blacks do not consider overweight to be unhealthy [43]. Given that black women's views about attractiveness and health are not closely associated with their weight status, weight loss messages [44-46] - which emphasize the importance of thinness - may have limited effectiveness among obese women. Intervention messages that emphasize weight gain prevention or enhancement of one's current shape may have greater sociocultural relevance, thus enhancing participant receptivity $[47,48]$.

Given the challenges associated with promoting weight loss among black women, particularly in the primary care setting, alternative treatment strategies are necessary. Weight gain prevention among overweight and Class 1 obese individuals is one such approach, one that requires relatively low treatment intensity and might be more consistent with the sociocultural experiences of black women. We suspect that its lower intensity and greater consistency with sociocultural norms may heighten participant responsiveness, improve intervention engagement, and enhance intervention outcomes among black women.

\section{Methods/Design}

We conduct the Shape Program (Shape), an 18-month randomized controlled trial of a weight gain prevention intervention for overweight and Class 1 obese (BMI: $25-34.9 \mathrm{~kg} / \mathrm{m}^{2}$ ) black female patients in the primary care setting. The primary outcome is weight maintenance over 12 months; secondary outcomes are change in obesity risk behaviors and obesity-related biomarkers, as well as maintenance of outcomes through 18-months. The primary hypothesis is that baseline BMI levels will be maintained in participants randomized to the intervention, while BMI levels will increase in those assigned to usual care.

All study procedures and protocols were approved by the Duke University Institutional Review Board and the Piedmont Health Board of Advisors.

\section{Setting}

Shape is conducted in six CHCs operated by Piedmont Health, a private, non-profit community health system that operates six health centers in a seven-county service 
area in central North Carolina. Each Piedmont Health center offers primary care services, with additional sitespecific services (e.g., laboratory, dentistry, pharmacy) that address local needs. Registered dietitians based at each health center provide WIC counseling, diabetes education, and medical nutrition therapy. Piedmont Health has a patient population of nearly 40,000 with over 123,900 medical/dental visits in 2010. Patients are predominately racial/ethnic minority (77\%), 98\% are $<200 \%$ of the federal poverty level, and most are either uninsured, underinsured, or hold public insurance $(59 \%$ uninsured, 31\% Medicaid/Medicare).

\section{Participants}

Participants include 194 premenopausal black women, aged 25 to 44 years, with a BMI of $25-34.9 \mathrm{~kg} / \mathrm{m}^{2}$. Additional inclusion criteria are: at least one visit to a Piedmont Health center in the prior 24 months, North Carolina residency, and the ability to read and write in English. Exclusion criteria include: current pregnancy, being $\leq 12$ months postpartum, a history of myocardial infarction or stroke in the prior two years, and profound cognitive, developmental or psychiatric disorders.

\section{Participant screening and recruitment}

Recruitment of participants occurred between September 2009 and February 2011. Piedmont Health staff used electronic medical record (EMR) data to generate lists of potentially eligible patients from each health center. Study staff abstracted patients' heights and weights from paper medical charts to assess BMI eligibility $\left(25-34.9 \mathrm{~kg} / \mathrm{m}^{2}\right)$.

Potential participants were sent invitation letters (signed by the respective health center medical director and the study principal investigator) and study brochures via postal mail. Patients could opt out of the study by calling the toll-free number provided in the recruitment letter. No patients opted out of the recruitment process. After one week, study staff called potentially eligible patients to invite participation, perform an initial eligibility assessment, and schedule a screening evaluation visit.

\section{Randomization}

Randomization occurred at the baseline visit, using a computer-based algorithm that was triggered after participants completed the baseline questionnaire battery. The randomization algorithm allocated participants equally (1:1) across treatment arms. We assigned participants to one of two research assistants and participants randomized to the intervention arm were randomly assigned to one of two interventionists. The intervention design precluded blinding either patients or interventionists to treatment assignment.

\section{Sample size}

The study is designed to detect a difference of $1.03 \mathrm{~kg} / \mathrm{m}^{2}$ in BMI at the 0.05 alpha level and $80 \%$ statistical power using a two-tailed test for differences. We increased the target sample size to account for examination of effect modifiers and mediators.

\section{Treatment arms}

\section{Usual care}

Usual care participants received the current standard of care offered by their primary care providers. In addition, usual care participants received semi-annual newsletters from our study team over the 12-month project period. These newsletters covered topics (e.g., finances, the environment) that were relevant to women in the target age group but did not relate to weight, nutrition, or physical activity.

\section{Weight maintenance intervention Theoretical framework}

Social Cognitive Theory (SCT) [49,50] informed the intervention's design. From SCT, self-efficacy was selected as the primary psychosocial mediator. There is strong and consistent evidence that self-efficacy is positively associated with weight loss intentions, initiation, and maintenance [51-53]. The intervention was designed to target each of the four factors that Bandura identified as influencing self-efficacy: [54] mastery experiences, social modeling, social persuasion, and somatic and emotional reactions. Social Cognitive Theory also indicates that behavior change can be facilitated through a number of self-regulatory processes that were built into the intervention, including self-monitoring [55,56], goal setting [53,57], and social support [58]. The intervention was designed to support these self-regulatory processes, which should further increase self-efficacy.

\section{Intervention design}

The intervention contained five components (Table 1): 1) obesogenic behavior change goals; 2) self-monitoring via interactive voice response (IVR) phone calls; 3 ) tailored skills training materials; 4) 12 interpersonal counseling calls; and 5) a 12-month YMCA membership.

\section{Behavior change goals}

The intervention utilized the interactive obesity treatment approach (iOTA), which creates an energy deficit sufficient to produce weight change through the modification of routine obesogenic lifestyle behaviors $[59,60]$. Participants were assigned 3 behavior change goals from the iOTA library using an algorithm that considers a participant's need for change, self-efficacy, readiness, and the goal's intended caloric deficit. The iOTA goal library contains over 21 obesogenic behavior change goals (e.g., five or 
Table 1 Intervention design

\begin{tabular}{lll}
\hline Component & Type of contact & Frequency of contacts (over 12-month period) \\
\hline Self-monitoring with tailored feedback & Printed tracking logs & Daily \\
& IVR calls & $1 /$ week \\
\hline Tailored skills training & Printed materials & 22/year \\
\hline Interpersonal counseling & Coaching calls from Registered Dietician & $1 /$ month \\
\hline Physical activity & YMCA membership & $12-$ month membership \\
\hline
\end{tabular}

more fruits and vegetables/day, no fast food, no sugar sweetened beverages, walking 7,000 steps/day) that were selected based on their: 1) empirical support; 2) population relevance; 3) ease of self-monitoring; and 4) concreteness. Participants were assigned new goals at months two and four to maintain motivation and facilitate goal mastery. At the beginning of each new goal assignment (every two months), participants received printed personalized feedback reports that detailed results of the previous goal assignments as well as provided tailored prescriptions for new assignments.

\section{Behavior change strategies Self-monitoring}

We recommended that participants self-monitor their iOTA behavior change goals daily using paper tracking logs. Participants were given pedometers to facilitate daily monitoring of physical activity. Participants relayed the self-monitoring data recorded on their tracking logs to the study team during weekly interactive voice response (IVR) calls. Interactive voice response calls allow one to interact with a computer system using a telephone by typing on the keypad or via speech. Participants received weekly IVR calls throughout the 12-month intervention. Self-monitoring data collected via IVR were visible to coaches to inform counseling activities during monthly coaching calls.

After self-monitoring data was collected, tailored feedback was immediately provided through IVR. Feedback messages described trends in participant progress, reinforced successes, and/or offered motivational strategies. Short skills training tips were also provided.

Shape utilized telephonic technologies for several reasons. First, IVR helps to overcome the literacy/numeracy barriers associated with detailed paper records. These systems have high reach $[61,62]$, as mobile phone penetration is very high in the target population. In contrast to web-based approaches, telephony is easily accessible, lowcost, quickly used, and requires no expert knowledge. Finally, IVR is inexpensive to develop, simple to tailor and immediately scalable.

\section{Skills training materials}

A major point of innovation in the Shape design is that, unlike traditional weight loss strategies, our approach suggests that participants maintain their current weight (and shape). This approach inherently embraces longheld social norms and aesthetic values. The intervention's focus resulted from qualitative pilot work designed to assess the acceptability of print materials and to test narrative messages.

Shape print materials were tailored at several levels. Participants received skills training content that corresponded to their behavior change goals. At baseline visits, participants were provided with a set of tailored intervention materials to be utilized over the first two months of the intervention. For example, individualized "Shape Tracking Logs" included tailored narratives based on each participant's unique set of goals. Additional materials were sent via postal mail every two months. We sent cyclespecific materials every two months in order to keep participants focused on the goals of current assignment and to heighten feelings of novelty and connection with the program. Participants also received quarterly newsletters with additional skills training information (e.g., appropriate portion sizes, food shopping tips, healthy recipes).

\section{Telephone counseling calls}

Each month, 20-minute counseling calls were delivered by Piedmont Health registered dietitians ("coaches") trained in motivational interviewing principles [63]. The coach calls were designed to enhance self-efficacy by guiding participants through identification of barriers to behavior change and resulting ambivalence towards change efforts. They also provided skills training and helped participants utilize goal-setting as a problem solving strategy.

Coaches used a web application that presented each session's call script, allowed for note taking, and provided access to participant self-monitoring data. The system recorded calls and automatically stored process data (e.g., date/time, call disposition, duration). Prior to the monthly counseling calls, coaches reviewed the participant self-monitored IVR goal tracking data that was held on the centralized data management system. The coaches used this data to guide discussions of participant progress towards assigned goals and to discuss readiness for behavior change and barriers to change. Data from the coaching calls were stored on the secure study server with all other study data for monitoring and data collection purposes.

Shape coaches participated in a 2-day training session at baseline and received biannual refresher trainings. Shape staff monitored IVR data for completeness and 
reviewed 5\% of coaching calls for adherence to protocol. Weekly supervision with the intervention coordinator ensured appropriate delivery of the coaching component of the intervention.

\section{YMCA}

Participants in the target population have limited options for safe and affordable physical activity. We addressed this barrier and promoted participant motivation for physical activity by providing intervention participants with 12-month memberships to local YMCAs.

\section{Data collection}

At the screening visit, research assistants oriented participants to the study, gathered informed consent, and collected anthropometric data to confirm BMI eligibility. The anthropometric and blood data collection activities were conducted at baseline and again at study follow-up visits at 6,12 , and 18 months.

\section{Anthropometric data}

Participants changed into hospital gowns and their body heights were measured to the nearest $0.1 \mathrm{~cm}$ using a calibrated wall-mounted stadiometer (Seca 214) [64] and body weights were measured to the nearest $0.1 \mathrm{~kg}$ using a portable electronic scale (Seca Model 876) [64]. Waist circumference was measured to the nearest $0.1 \mathrm{~cm}$ using a vinyl, retractable tape measure (AccuFitness MyoTape) where circumference was measured horizontally from the highest point of the iliac crest at minimal respiration. The Omron HEM 907XL, a microprocessor controlled, noninvasive device that automatically measures systolic pressure, diastolic pressure, and pulse rate for adults, was used to measure blood pressure three times at 1-minute intervals after five minutes of quiet sitting. Participants were advised not to smoke or to consume any caffeine within 30 minutes of their study visits.

\section{Cardiometabolic biomarkers}

Participants were instructed to fast for at least eight hours prior to their study visits. Each participant had a fasting glucose and lipid panel analyzed using fingerstick blood specimens collected in $40 \mu \mathrm{l}$ capillary tubes (Cholestech LDX; Cholestech Corporation, Hayward, CA, USA).

\section{Physical activity}

All participants (Intervention and Usual Care) wore accelerometers (Actical; Philips Respironics, Inc., Bend, OR USA) on their non-dominant wrists [65] to provide estimates of free-living physical activity before baseline and after 12-month visits. Participants were instructed to wear the monitors continuously until their return visits approximately 14 days later. Upon its return, the activity monitor was removed from the wrist and data was downloaded to a computer and visually screened for compliance and collection errors. Complete files were defined as those in which the monitor had been worn for $\geq 10$ days (i.e., complete compliance).

Activity monitor files were first transformed from 15-sec to 1-min epochs and then "smoothed" using a protocol validated for wrist monitoring of physical activity in overweight and obese adults [66]. Next, the resulting data were transformed into units of activity energy expenditure (AEE; $\mathrm{kcals} / \mathrm{kg} / \mathrm{min}$ ) using a 2R calibration algorithm [67] and then summarized into outcome variables that included time ( $\mathrm{T}$; mins/week) and activity energy expenditure (AEE; kcals/week) engaged in light $\left(T_{L}\right.$ and $A_{E} E_{L}$, respectively) and moderate-vigorous ( $\mathrm{T}_{\mathrm{MV}}$ and $\mathrm{AEE}_{\mathrm{MV}}$, respectively) activity intensities. The cut point used to distinguish light from moderate intensity activities was $0.0385 \mathrm{kcals} / \mathrm{kg} / \mathrm{min}$, which is the same value defined previously for overweight and obese adults [68]. Finally, both $T_{M V}$ and $A_{E E}$ variables were summarized in activity bouts of 1 and 10 minutes. These data-screening and processing procedures were consistent with those recently recommended for use with accelerometry-based physical activity data [69].

\section{Survey data}

Participants complete self-report surveys at baseline and 6-, 12-, and 18-month follow-up. Surveys are administered via computer using an online survey tool (www.surveygizmo.com). Demographic variables collected at baseline include age, race/ethnicity, marital status, occupational status, educational attainment, income, and comorbidities.

We used validated measures to assess a range of relevant constructs, including:

Body image The 14-item Figure Rating Scale (FRS) is designed to assess current and past body size as well as attractiveness of body figure drawings [70].

Quality of life The 5-item EuroQol instrument (EQ-5D) assesses mobility, self-care, usual activities, pain/discomfort, and anxiety/depression. The EuroQol visual analog scale (EQ-VAS) is similar to a health thermometer and is designed to assess self-rated health quality of life [71,72].

Medical history Twelve items measure general health and previous diagnosis and perceived risk of diabetes and high blood pressure.

Physical activity Four items are used to assess current stage of change in relation to physical activity. A 6-item scale from the Behavioral Risk Factor Surveillance System (BRFSS) is designed to assess the amount and frequency of moderate and vigorous activity $[73,74]$. 
Tobacco use Three items assess current smoking behaviors and previous quit attempts. This measure is derived from the National Health Interview Survey (NHIS) [75].

Sleep behavior The Medical Outcomes Study (MOS) Sleep is a 12-item measure designed to assess minutes to fall asleep, total hours of sleep each night, and difficulties with sleep. The questionnaire assesses six dimensions: sleep disturbance, sleep adequacy, daytime somnolence, snoring, short of breath, and quantity of sleep [76].

Self-efficacy for exercise Self-efficacy for exercise is measured using five items that assess confidence in ability to exercise when tired, in a bad mood, don't have time, on vacation, or when it is raining/snowing [77].

Genetic causal beliefs An 8-item scale is designed to assess perceptions of risk for obesity, diabetes, and heart disease (i.e., genetic or behavioral lifestyle habits) $[78,79]$.

Dietary restraint The Three Factor Eating Questionnaire is designed to assess different dimensions of eating behavior. For the current study, we used the 18-item revised version (TFEQ-R18) to measure three domains: Cognitive Restraint (6 items), Uncontrolled Eating (9 items), and Emotional Eating (3 items) [80,81].

Social support A 19-item subscale from the Medical Outcomes Study (MOS-SSS) assesses availability of social support. Four subscales are used: emotional/informational, tangible, affectionate, and positive social interaction [82].

Perceived weight A 12-item scale is designed to assess perceptions of past, current, and future weight, selfperceived weight class (i.e., underweight, average weight, overweight), and body satisfaction.

Negative life events A 16-item questionnaire measures frequency of stressful life events [83].

Depression The 8-item Patient Health Questionnaire (PHQ-8) is designed to assess the presence of depressive symptoms [84].

Health literacy A 3-item questionnaire is used to screen for limited health literacy [85].

Neighborhood environment The physical activity environment questions include items adapted from the Neighborhood Environment Walkability Scale (NEWS) on perceptions of the built environment, land use mix, and community support for physical activity [86].
Food security An adaptation of the USDA Household Food Security Scale (6 items) is designed to assess household food security (money for food, food affordability, skipped meals) [87-89].

Racial identity The 8-item Centrality subscale of the Multidimensional Inventory of Black Identity (MIBI) is used to measure African-American or black racial identity [90].

Absenteeism and presenteeism The 11 items from the World Health Organization Health and Work Performance Questionnaire (HPQ)-Short Form assess number of hours worked, expected hours of work, missed work, total hours of work over the past 4 weeks, and perceived job performance [91,92].

\section{Data analysis}

Shape will be evaluated using the RE-AIM planning and evaluation framework [93] (Table 2). The RE-AIM framework addresses five issues related to both internal and external validity by comprehensively evaluating the success of interventions on issues key for translation from research to practice and dissemination: 1) Reach and representativeness of individuals who participate; 2) Effectiveness/Efficacy of the intervention on the primary outcomes at the individual level; 3) Adoption at the organizational/CHC level; 4) Implementation measured at the $\mathrm{CHC}$ provider/staff level; and 5) Maintenance at both the individual participant and provider level.

\section{Baseline characteristics}

A total of 194 black female patients were randomized to treatment arms. Five participants became ineligible after randomization due to pregnancy or diagnosis of cancer. At baseline (Table 3), participants were an average of 35.4 (SD $=5.5)$ years old with an average BMI of 30.2 $(\mathrm{SD}=2.6) \mathrm{kg} / \mathrm{m}^{2}$. Participants were mostly employed (70.4\%) and low-income - 73.5\% had an annual household income $\leq \$ 29,999$ and one-third lived beneath the federal poverty threshold. Participants were supporting an average of $3.2(\mathrm{SD}=1.3)$ persons with their household income. Most participants (72.5\%) did not live with partners in the household. One-third of the sample had a high school diploma, GED or less and only $7 \%$ had completed college.

Accelerometers placed at screening visits were returned an average of 15.1 days after initial placement. Complete baseline accelerometer data was collected for $87.6 \%$ of the participants $(n=170)$. Nearly a third $(31.6 \%)$ of participants met the federal guideline of $\geq 150$ minutes of 10-minute bouts of physical activity each week. Participants averaged $166.9(\mathrm{SD}=265.5)$ minutes a week of moderate physical activity in 10-minute bouts and no 
Table 2 RE-AIM Measures

\begin{tabular}{|c|c|c|c|}
\hline Domain & Description [94] & Measure & Data source(s) \\
\hline Reach & $\begin{array}{l}\text { Degree to which target } \\
\text { population is reached by } \\
\text { study activities }\end{array}$ & $\begin{array}{l}\text { 1. \% Eligible population contacted } \\
\text { 2. \% Who respond to contact } \\
\text { 3. \% Who participate/are excluded } \\
\text { 4. Representativeness of study sample } \\
\text { to target population }\end{array}$ & $\begin{array}{l}\text { 1-4. Study database } \\
\text { 1-4. PHS EHR }\end{array}$ \\
\hline Efficacy & $\begin{array}{l}\text { Improvement in study } \\
\text { outcomes }\end{array}$ & $\begin{array}{l}\text { 1. Change in weight and secondary } \\
\text { outcome measures }\end{array}$ & 1. In-person measurement \\
\hline Adoption & $\begin{array}{l}\text { Potential organizational } \\
\text { uptake }\end{array}$ & 1. Patient intervention satisfaction & 1. Survey (12 mo) \\
\hline Implementation [95] & $\begin{array}{l}\text { Degree to which intervention } \\
\text { is implemented as intended }\end{array}$ & $\begin{array}{l}\text { 1. Interventionist adherence to } \\
\text { counseling protocol } \\
\text { 2. Participant adherence to intervention }\end{array}$ & $\begin{array}{l}\text { 1. Study database } \\
\text { 1. Process measures including: } \\
\text { supervisor review of coach call } \\
\text { recordings, of \# attempted } \\
\text { and completed coach calls, of timing } \\
\text { and accuracy of mailed materials } \\
\text { 1. Patient survey (baseline, } 6,12 \text { mo) } \\
\text { 2. \# attempted and completed coach } \\
\text { and IVR calls } \\
\text { 2. \# participant YMCA visits }\end{array}$ \\
\hline Maintenance & $\begin{array}{l}\text { Can program outcomes be } \\
\text { sustained over time? }\end{array}$ & 1. Weight change at 18 months & $\begin{array}{l}\text { 1. Patient survey }(18 \mathrm{mo}) \\
\text { 1. PHS EHR }\end{array}$ \\
\hline Cost & $\begin{array}{l}\text { How much does intervention } \\
\text { cost? }\end{array}$ & $\begin{array}{l}\text { 1. Cost of staff time (coach } \\
\text { and research staff) devoted to conducting } \\
\text { intervention activities } \\
\text { 2. Cost of intervention delivery: print } \\
\text { materials, technology costs, YMCA memberships }\end{array}$ & $\begin{array}{l}\text { 1. Study database } \\
\text { 1. Staff time diaries } \\
\text { 2. Financial statements }\end{array}$ \\
\hline
\end{tabular}

(0.0) minutes a week of vigorous activity in 10-minute bouts.

Almost half (46.0\%) of the sample reported a diagnosis of hypertension or prehypertension and $12 \%$ reported a diagnosis of diabetes or prediabetes. Almost one-third of participants smoked and over one-fifth scored above the PHQ clinical threshold for depression. Mean blood pressure measurements were: $\mathrm{SBP}=123.2$ $(\mathrm{SD}=14.8) / \mathrm{DBP}=80.6 \quad(\mathrm{SD}=11.0)$. Mean lipid levels were optimal or close to optimal.

\section{Discussion}

Despite the recent plateau of the obesity epidemic in the U.S. adult population [1], black women still have dramatically higher obesity risk compared to other groups. Given evidence suggesting that overweight (and Class 1 obesity) is less health damaging for black women compared to other $\mathrm{racial} / \mathrm{ethnic}$ groups, maintaining weight status among black women in the $\mathrm{BMI} \leq 35 \mathrm{~kg} / \mathrm{m}^{2}$ range may hold promise as an alternative obesity treatment strategy. Strategies are needed that can prevent weight gain for women in the $\mathrm{BMI} \leq 35 \mathrm{~kg} / \mathrm{m}^{2}$ range, those who might benefit most from weight gain prevention approaches. Fortunately, weight gain prevention can be accomplished at lower treatment intensity than can weight loss [96]. A major advantage for this population is that weight gain prevention builds upon existing weight-related sociocultural norms among black women instead of challenging them. In stark contrast to the focus of weight loss interventions, Shape's content focused on "maintaining shapes" and "showing off curves" in order to validate sociocultural norms about body image and to reinforce self-affirming weight maintenance messages.

Furthermore, Shape was designed for primary care practice - a particularly meaningful setting for addressing the obesity epidemic and one in which relatively few weight-related trials are conducted. More specifically, the intervention was developed for implementation in community health centers, critical primary care delivery systems for our nation's most medically vulnerable populations. Indeed, the baseline characteristics of the Shape sample reflect a group that is at extremely high risk for obesity and obesity-associated chronic disease. The sample was composed of largely rural, black women who are unmarried, supporting several family members, and struggling to make ends meet. About half of the sample was diagnosed with hypertension or prehypertension. Participants demonstrated elevated levels of moderate physical activity (that was likely due primarily to occupational pursuits) and no vigorous activity, which suggests little intentional exercise. Many women (over 20\%) in our sample were above the clinical threshold for depression. Together, this group is one at extremely high disease risk and, yet, one for which we have few evidence-based intervention approaches.

Although Shape is a novel approach executed in an understudied population, we are encouraged by our 
Table 3 Baseline characteristics of the Shape Program analytic sample $(n=189)$

\section{Variable}

$\mathrm{N}$ (percent)

Race/ethnicity

Black or African American

$189(100.0)$

More than 1 race

$11(5.8)$

Education

\begin{tabular}{|c|c|}
\hline Less than high school graduate & $19(10.0)$ \\
\hline High school graduate or GED & $45(23.8)$ \\
\hline Some college or vocational/trade school & $83(43.9)$ \\
\hline Associate degree & $26(13.8)$ \\
\hline College graduate or post graduate degree & $13(6.9)$ \\
\hline Unknown & $3(1.6)$ \\
\hline \multicolumn{2}{|l|}{ Annual household income } \\
\hline Under $\$ 10,000-\$ 29,999$ & $139(73.5)$ \\
\hline$\$ 30,000-\$ 39,999$ & $24(12.7)$ \\
\hline Over $\$ 40,000$ & $24(12.7)$ \\
\hline Unknown & $2(1.1)$ \\
\hline People supported by this income: mean (SD) & $3.2(1.3)$ \\
\hline Living under U.S. Census poverty threshold & $62(33.3)$ \\
\hline \multicolumn{2}{|l|}{ Marital status } \\
\hline Married & $48(25.4)$ \\
\hline Widowed, divorced, separated & $44(23.3)$ \\
\hline Never married & $78(41.3)$ \\
\hline Not married or living with partner & $15(7.9)$ \\
\hline Unknown & $4(2.1)$ \\
\hline \multicolumn{2}{|l|}{ Current employment } \\
\hline Yes & $133(70.4)$ \\
\hline No & $53(28.0)$ \\
\hline Unknown & $3(1.6)$ \\
\hline Current smoker & $58(30.7)$ \\
\hline \multicolumn{2}{|l|}{ Self-reported history of: } \\
\hline Diabetes or prediabetes & $23(12.2)$ \\
\hline Hypertension or prehypertension & $87(46.0)$ \\
\hline Meeting U.S Federal guidelines for physical activity using accelerometers & $49(31.6)$ \\
\hline Depression score: mean (SD) & $6.2(4.9)$ \\
\hline Depression score $\geq 10$ & $38(20.1)$ \\
\hline
\end{tabular}

Depression score $\geq 10$

Mean (SD)

\section{Age (yrs)}

Weight (kg)

$35.4(5.5)$

BMI $\left(\mathrm{kg} / \mathrm{m}^{2}\right)$

$81.2(8.8)$

Waist circumference $(\mathrm{cm})$

$30.2(2.6)$

Blood pressure: systolic $(\mathrm{mmHg})$

$97.8(8.2)$

Blood pressure: diastolic $(\mathrm{mmHg})$

$123.2(14.8)$

Lipids

\begin{tabular}{lr}
\hline Triglycerides $(\mathrm{mg} / \mathrm{dL})$ & $102.2(47.5)$ \\
\hline $\mathrm{LDL}(\mathrm{mg} / \mathrm{dL})$ & $107.4(34.2)$ \\
\hline $\mathrm{HDL}(\mathrm{mg} / \mathrm{dL})$ & $53.8(16.1)$ \\
\hline Total cholesterol $(\mathrm{mg} / \mathrm{dL})$ & $179.2(37.3)$ \\
\hline Fasting glucose $(\mathrm{mg} / \mathrm{dL})$ & $105.1(44.3)$ \\
\hline
\end{tabular}

Fasting glucose (mg/dL) 
initial success with recruitment and retention. To optimize participant recruitment and retention, the study team employed several strategies designed to accommodate the busy lives of study participants, most of whom work, are socioeconomically disadvantaged, and are solely responsible for children in the household. Study visits were offered in a number of locations convenient to participants, including in the Piedmont Health centers, at all times of day on weekdays and weekends. Participants who notified the study team about transportation difficulties were offered home visits and taxi vouchers for evaluation visits.

The research team worked closely and collaboratively with Piedmont Health partners on Shape design and implementation issues. The research team designed recruitment and data collection activities to be minimally burdensome on health center practices, while harnessing the strengths of the Piedmont Health system. Financial mechanisms were negotiated that adequately reimbursed Piedmont Health for its involvement and for the staff time of its registered dietitians, who functioned as study coaches. These types of strategies are crucial in ensuring that $\mathrm{CHC}$-based research benefits patients without overburdening already-strained clinical operations.

In conclusion, black women are disproportionally affected by the epidemic of obesity and, consequently, the risk of comorbidities associated with being obese. In previous trials, low-income black women have not been as well represented as other groups; when included, their weight loss outcomes have been suboptimal. Shape was designed to take an innovative approach to managing obesity and its health consequences among black women by integrating behavior change theory, building upon an understanding of sociocultural norms and utilizing health information technologies. In these ways, Shape was designed to be responsive to calls for interventions that have dissemination potential in real world practice settings. Such considerations are particularly pressing for socioeconomically disadvantaged populations given their dramatically increased risk of obesity and obesityassociated chronic diseases and the limited availability of obesity treatment options.

\footnotetext{
Abbreviation

CVD: Cardiovascular disease; CHC: Community health center; EMR: Electronic medical record; SCT: Social cognitive theory; iOTA: Interactive obesity treatment approach; IVR: Interactive voice response; AEE: Activity energy expenditure; T: Time; FRS: Figure rating scale; BRFSS: Behavioral risk factor surveillance system; NHIS: National health interview survey; MOS: Medical outcomes study; PHQ: Patient health questionnaire; MIBI: Multidimensional inventory of black identity.
}

\section{Competing interests}

The authors declare that they have no competing interests.

\section{Acknowledgements}

This trial is funded by grant R01DK078798. Dr. Emmons was supported by K05CA124415 and Dr. Bennett was supported by K22CA126992. We express deep gratitude to the administration and staff of Piedmont Health for their continued collaboration and participation in the Shape Program. In particular, we would like to thank Brian Toomey, MSW, Tom Wroth, MD, MPH, Heather Miranda, RD, LDN, Marni Holder, RN, FNP-BC, Ashley Brewer, RD, LDN, Greg Wheatley, MPH, RD, LDN, Kristen Norton, MA, RD, LDN, Marianne Ratcliffe, $\mathrm{MHA}$ and staff at the PHS health centers for their support. We are grateful to Martha Zorn, MS at the University of Massachusetts-Amherst for her assistance with data analysis and to Lisa Englert for her assistance with manuscript preparation. Lastly, we would like to especially thank the women participating in Shape.

\section{Author details}

'Duke Obesity Prevention Program, Duke Global Health Institute, 2812 Erwin Road, Suite 403 Box 90392, Durham, NC 27705, USA. ${ }^{2}$ School of Public Health and Health Sciences, University of Massachusetts Amherst, 425 Arnold House 715 North Pleasant Street, Amherst, MA 01003-9304, USA. ${ }^{3}$ College of Nursing and Health Sciences, University of Massachusetts Boston, 100 Morrissey Boulevard, Boston, MA 02125, USA. ${ }^{4}$ Division of Endocrinology, Metabolism and Nutrition, Duke University Medical Center, 200 Trent Drive, Duke South Orange Zone DUMC, Box 3031, Durham, NC 27710, USA. ${ }^{5}$ Department of Health \& Human Development, Montana State University, H\&PE Complex, Hoseaus Room 121, Bozeman, MT 59717, USA. ${ }^{6}$ Dana-Farber Cancer Institute, 450 Brookline Avenue, LW601, Boston, MA 02215, USA.

\section{Authors' contributions}

PF managed study design and execution and drafted the manuscript for publication. EL and JW coordinated intervention design. BB consulted on data safety and execution of the study. DH consulted on the accelerometer data collection protocols and analyzed accelerometer data. EP and SA participated in study design and conducted statistical analysis. DD, VL, ML and JM conducted primary data collection and participated in study design. KE participated in study conceptualization and design. GB conceived of the study, acquired study funding, participated in study design and coordination and drafted the manuscript for publication. All authors read and approved the final manuscript.

\section{Authors' information}

DD is now with Quintiles Transnational in Durham, NC and VL is now with the School of Social Work at the University of North Carolina, Chapel Hill, NC.

Received: 10 April 2012 Accepted: 26 April 2012

Published: 26 April 2012

\section{References}

1. Flegal KM, Carroll MD, Kit BK, Ogden CL: Prevalence of obesity and trends in the distribution of Body Mass Index among US adults, 1999-2010. JAMA 2012, 307(5):491-497.

2. Flegal KM, Carroll MD, Ogden $C L$, Curtin LR: Prevalence and trends in obesity among US adults, 1999-2008. JAMA 2010, 303(3):235-241.

3. Centers for Disease Control: Trends in the Health of Americans Hyattsville, MD; 2004.

4. Morland K, Wing S: Diez Roux A, Poole C: Neighborhood characteristics associated with the location of food stores and food service places. Am J Prev Med 2002, 22(1):23-29.

5. Morland K, Wing S, Roux AD: The contextual effect of the local food environment on residents' diets: the atherosclerosis risk in communities study. Am J Public Health 2002, 92(11):1761.

6. Ogden CL, National Center for Health Statistics (US): Obesity and socioeconomic status in adults: United States, 2005-2008: US Department of Health and Human Services, Centers for Disease Control and Prevention, National Center for Health Statistics; Hyattsville, MD; 2010

7. Sinclair J, Lawson B, Burge F: Which patients receive advice on diet and exercise? Canadian Family Physician 2008, 54(3):404-412.

8. Bleich SN, Pickett-Blakely O, Cooper LA: Physician practice patterns of obesity diagnosis and weight-related counseling. Patient Educ Couns 2011, 82(1):123-129.

9. Bennett GG, Warner ET, Glasgow RE, Askew S, Goldman J, Ritzwoller DP, Emmons KM, Rosner BA, Colditz GA: Obesity Treatment for Socioeconomically Disadvantaged Patients in Primary Care Practice. Arch Intern Med 2012, 172(7):565-574. 
10. Osei-Assibey G, Kyrou I, Adi Y, Kumar S, Matyka K: Dietary and lifestyle interventions for weight management in adults from minority ethnic/ non-White groups: a systematic review. Obes Rev 2010, 11(11):769-776.

11. Yancey AK, Kumanyika SK, Ponce NA, McCarthy WJ, Fielding JE, Leslie JP, Akbar J: Population-based interventions engaging communities of color in healthy eating and active living: a review. Preventing Chronic Disease 2004, 1(1):A09.

12. Kumanyika S, Wilson JF, Guilford-Davenport M: Weight-related attitudes and behaviors of black women. J Am Diet Assoc 1993, 93(4):416-422.

13. Neve M, Morgan PJ, Jones P, Collins C: Effectiveness of web-based interventions in achieving weight loss and weight loss maintenance in overweight and obese adults: a systematic review with meta-analysis. Obes Rev 2010, 11(4):306-321.

14. Kumanyika SK, Gary TL, Lancaster KJ, Samuel-Hodge CD, Banks-Wallace J, Beech BM, Hughes-Halbert C, Karanja N, Odoms-Young AM, Prewitt TE: Achieving healthy weight in African-American communities: research perspectives and priorities. Obesity 2005, 13(12):2037-2047.

15. Wareham NJ, van Sluijs EMF, Ekelund U: Physical activity and obesity prevention: a review of the current evidence. Proc Nutr Soc 2005, 64(02):229-247.

16. World Health Organization: Obesity: preventing and managing the global epidemic. World Health Organization Technical Report. Volume 894. Geneva: World Health Organization. WHO Technical Report Series; 2000.

17. Gill TP: Key issues in the prevention of obesity. Br Med Bull 1997, 53(2):359.

18. Mokdad AH, Ford ES, Bowman BA, Dietz WH, Vinicor F, Bales VS, Marks JS: Prevalence of obesity, diabetes, and obesity-related health risk factors, 2001. JAMA 2003, 289(1):76-79.

19. Visscher T, Kromhout D, Seidell J: Long-term and recent time trends in the prevalence of obesity among Dutch men and women. Int J Obes 2002, 26(9):1218-1224

20. Ogden $\mathrm{CL}$, Flegal KM, Carroll MD, Johnson CL: Prevalence and trends in overweight among US children and adolescents, 1999-2000. JAMA 2002, 288(14):1728-1732

21. Carpenter C, Ross R, Paganini-Hill A, Bernstein L: Lifetime exercise activity and breast cancer risk among post-menopausal women. $\mathrm{Br} J$ Cancer 1999, 80(11):1852.

22. Hu FB, Stampfer MJ, Solomon C, Liu S, Colditz GA, Speizer FE, Willett WC, Manson JAE: Physical activity and risk for cardiovascular events in diabetic women. Ann Intern Med 2001, 134(2):96-105.

23. Roberts RE, Deleger S, Strawbridge WJ, Kaplan GA: Prospective association between obesity and depression: evidence from the Alameda County Study. Int J Obes 2003, 27(4):514-521.

24. Vainio $H$, Bianchini F: Weight control and physical activity: World Health Organization. Lyon, France; 2002.

25. Stevens J, Cai J, Jones DW: The effect of decision rules on the choice of a body mass index cutoff for obesity: examples from African American and white women. Am J Clin Nutr 2002, 75(6):986-992.

26. Dustan HP: Obesity and hypertension in blacks. Cardiovascular drugs and therapy 1990, 4:395-402.

27. Pan SY, Johnson KC, Ugnat AM, Wen SW, Mao Y: Association of obesity and cancer risk in Canada. Am J Epidemiol 2004, 159(3):259-268.

28. Pan WH, Flegal KM, Chang HY, Yeh WT, Yeh CJ, Lee WC: Body mass index and obesity-related metabolic disorders in Taiwanese and US whites and blacks: implications for definitions of overweight and obesity for Asians. Am J Clin Nutr 2004, 79(1):31.

29. Stevens J, Plankey MW, Williamson DF, Thun MJ, Rust PF, Palesch Y, O'Neil PM: The body mass index-mortality relationship in white and African American women. Obes Res 1998, 6(4):268-277.

30. Stevens J, Keil JE, Rust PF, Tyroler H, Davis C, Gazes PC: Body mass index and body girths as predictors of mortality in black and white women Arch Intern Med 1992, 152(6):1257

31. Wing RR, Matthews KA, Kuller LH, Meilahn EN, Plantinga PL: Weight gain at the time of menopause. Arch Intern Med 1991, 151(1):97.

32. Despres JP, Moorjani S, Lupien PJ, Tremblay A, Nadeau A, Bouchard C: Regional distribution of body fat, plasma lipoproteins, and cardiovascular disease. Arterioscler Thromb Vasc Biol 1990, 10(4):497-511.

33. Flynn KJ, Fitzgibbon M: Body images and obesity risk among black females: a review of the literature. Annals of behavioral medicine 1998, 20(1):13-24

34. Roberts A, Cash TF, Feingold A, Johnson BT: Are black-white differences in females' body dissatisfaction decreasing? A meta-analytic review. $J$ Consult Clin Psychol 2006, 74(6):1121.
35. Sabik NJ, Cole ER, Ward LM: Are all minority women equally buffered from negative body image? Intra-ethnic moderators of the buffering hypothesis. Psychol Women Q 2010, 34(2):139-151.

36. Striegel-Moore RH, Wilfley DE, Caldwell MB, Needham ML, Brownell KD: Weight-related attitudes and behaviors of women who diet to lose weight: a comparison of black dieters and white dieters. Obes Res 1996, 4(2):109-116.

37. Stevens J, Kumanyika SK, Keil JE: Attitudes toward body size and dieting: differences between elderly black and white women. Am J Public Health 1994, 84(8):1322

38. Smith DE, Thompson JK, Raczynski JM, Hilner JE: Body image among men and women in a biracial cohort: the CARDIA Study. Int J Eat Disord 1999, 25(1):71-82

39. Powell AD, Kahn AS: Racial differences in women's desires to be thin. Int J Eat Disord 1995, 17(2):191-195.

40. Altabe M: Ethnicity and body image: quantitative and qualitative analysis. Int J Eat Disord 1998, 23(2):153-159.

41. Kuchler F, Variyam J: Mistakes were made: misperception as a barrier to reducing overweight. Int J Obes 2003, 27(7):856-861.

42. Paeratakul S, White MA, Williamson DA, Ryan DH, Bray GA: Sex, race/ ethnicity, socioeconomic status, and BMI in relation to self-perception of overweight. Obesity 2002, 10(5):345-350

43. Bennett GG, Wolin KY, Goodman M, Samplin-Salgado M, Carter P, Dutton S, Hill R, Emmons K: Attitudes regarding overweight, exercise, and health among blacks (United States). Cancer Causes and Control 2006, 17(1):95-101.

44. Malpede CZ, Greene LF, Fitzpatrick SL, Jefferson WK, Shewchuk RM, Baskin ML, Ard JD: Racial influences associated with weight-related beliefs in African American and Caucasian women. Ethn Dis 2007, 17(1):1-5.

45. Gluck ME, Geliebter A: Racial/ethnic differences in body image and eating behaviors. Eat Behav 2002, 3(2):143-151.

46. Ard JD: Unique perspectives on the obesogenic environment. Journal of general internal medicine 2007, 22(7):1058-1060.

47. Blixen $C E$, Singh $A, X u$ M, Thacker $H$, Mascha E: What women want: understanding obesity and preferences for primary care weight reduction interventions among African-American and Caucasian women. J Natl Med Assoc 2006, 98(7):1160.

48. Viner R, Haines M, Taylor S, Head J, Booy R, Stansfeld S: Body mass, weight control behaviours, weight perception and emotional well being in a multiethnic sample of early adolescents. Int J Obes 2006, 30(10):1514-1521.

49. Bandura A: Self-efficacy: The Exercise of Control. New York: Freeman; 1997.

50. Bandura A: Self-efficacy: toward a unifying theory of behavioral change. Psychol Rev 1977, 84(2):191.

51. Linde JA, Rothman AJ, Baldwin AS, Jeffery RW: The impact of self-efficacy on behavior change and weight change among overweight participants in a weight loss trial. Heal Psychol 2006, 25(3):282.

52. Richman RM, Loughnan GT, Droulers AM, Steinbeck KS, Caterson ID: Self-efficacy in relation to eating behaviour among obese and non-obese women. Int J Obes Relat Metab Disord 2001, 25(6):907-913.

53. Elfhag $K$, Rossner $\mathrm{S}$ : Who succeeds in maintaining weight loss? A conceptual review of factors associated with weight loss maintenance and weight regain. Obes Rev 2005, 6(1):67-85.

54. Bandura A: Health promotion from the perspective of social cognitive theory. Psychol Heal 1998, 13(4):623-649.

55. Levitsky D, Garay J, Nausbaum M, Neighbors L, Dellavalle D: Monitoring weight daily blocks the freshman weight gain: a model for combating the epidemic of obesity. Int J Obes 2006, 30(6):1003-1010.

56. Klem ML, Wing RR, McGuire MT, Seagle HM, Hill JO: A descriptive study of individuals successful at long-term maintenance of substantial weight loss. Am J Clin Nutr 1997, 66(2):239-246.

57. Strecher $V$ : Internet methods for delivering behavioral and health-related interventions (eHealth). Annu Rev Clin Psychol 2007, 3:53-76.

58. Wing RR, Jeffery RW: Benefits of recruiting participants with friends and increasing social support for weight loss and maintenance. J Consult Clin Psychol 1999, 67(1):132-138

59. Bennett GG, Herring SJ, Puleo E, Stein EK, Emmons KM, Gillman MW: Web-based weight loss in primary care: a randomized controlled trial. Obesity 2009, 18(2):308-313.

60. Greaney ML, Quintiliani LM, Warner ET, King DK, Emmons KM, Colditz GA Glasgow RE, Bennett GG: Weight management among patients at community health centers: The "Be Fit, Be Well" study. Obesity and Weight Management 2009, 5(5):222-228.

61. Piette JD: Enhancing support via interactive technologies. Curr Diab Rep 2002, 2(2):160-165 
62. Ramelson HZ, Bassey B, Friedman RH: The use of computer telephony to provide interactive health information. AMIA Annu Symp Proc 2003 2003:539-543.

63. Miller W, Rollnick S: Motivational Interviewing: Preparing People To Change Addictive Behaviors. New York: Guilford Press; 1993.

64. Centers for Disease Control and Prevention. National Health and Nutrition Examination Survey Protocol. Hyattsville: U.S. Department of Health and Human Services, Centers for Disease Control and Prevention; 2007

65. Heil DP, Bennett GG, Bond KS, Webster MD, Wolin KY: Influence of activity monitor location and bout duration on free-living physical activity. Res $Q$ Exerc Sport 2009, 80(3):424-433.

66. Heil DP, Hymel AM, Martin CK: Predicting free-living activity energy expenditure with hip and wrist accelerometry versus double labeled water. Medicine \& Science in Sports \& Exercise 2009, 41(5):447.

67. Heil DP: Predicting activity energy expenditure using the Actical activity monitor. Res Q Exerc Sport 2006, 77(1):64-80.

68. Heil DP, Whitt-Glover MC, Brubaker P: H, Mori Y: Influence of moderate intensity cut point on free-living physical activity outcome variables. Med Sci Sports Exerc 2007, 39(suppl 5):S185.

69. Heil DP, Brage S, Rothney MP: Modeling physical activity outcomes from wearable monitors. Med Sci Sports Exerc 2012, 44(1 Suppl 1):S50-S60.

70. Stunkard AJ, Sørensen T, Schulsinger F: Use of the Danish Adoption Register for the study of obesity and thinness. Research publicationsAssociation for Research in Nervous and Mental Disease 1983, 60:115-120.

71. Brooks R: EuroQol: the current state of play. Health Policy 1996, 37(1):53-72.

72. Dolan P: Modeling valuations for EuroQol health states. Med Care 1997, 35(11):1095-1108.

73. Centers for Disease Control and Prevention: Behavioral Risk Factor Surveillance System user's guide. Atlanta: U.S. Department of Health and Human Services, Centers for Disease Control and Prevention; 1998

74. Marcus B: Forsyth LA: Motivating People to be Physically Active: Champaign. IL: Human Kinetics; 2003.

75. National Center for Health Statistics: Data file documentation, National Health Interview Survey, 2005. Ann Arbor, Ml; 2006.

76. Hays RD, Stewart AL: Sleep measures. In Measuring functioning and wellbeing: The Medical Outcomes Study approach. Edited by Stewart AL, Ware JE. Durham, N.C: Duke University Press; 1992:235-259.

77. Marcus BH, Selby VC, Niaura RS, Rossi JS: Self-efficacy and the stages of exercise behavior change. Research quarterly for exercise and sport 1992, 63(1):60-66.

78. Ashida S, Goodman M, Pandya C, Koehly L, Lachance C, Stafford J, Kaphingst $\mathrm{K}$ : Age differences in genetic knowledge, health literacy and causal beliefs for health conditions. Public Health Genomics 2011, 14(4-5):307-316.

79. Weinman J, Petrie KJ, Moss-Morris R, Horne R: The Illness Perception Questionnaire: A new method for assessing the cognitive representation of illness. Psychol Health 1996, 11:431-445.

80. Karlsson J, Persson LO, Sjostrom L, Sullivan M: Psychometric properties and factor structure of the Three-Factor Eating Questionnaire (TFEQ) in obese men and women. Results from the Swedish Obese Subjects (SOS) study. Int J Obes Relat Metab Disord 2000, 24(12):1715-1725.

81. Stunkard AJ, Messick S: The three-factor eating questionnaire to measure dietary restraint, disinhibition and hunger. J Psychosom Res 1985, 29(1):71-83.

82. Sherbourne CD, Stewart AL: The MOS Social Support Survey. Social Science \& Medicine 1991, 32(6):705-714.

83. Friedman GD, Cutter GR, Donahue RP, Hughes GH, Hulley SB, Jacobs DR, Liu K, Savage PJ: CARDIA: study design, recruitment, and some characteristics of the examined subjects. J Clin Epidemio/ 1988, 41(11):1105-1116.

84. Kroenke K, Strine TW, Spitzer RL, Williams JBW, Berry J, Mokdad AH: The PHQ-8 as a measure of current depression in the general population. $J$ Affect Disord 2009, 114(1-3):163-173.

85. Chew LD, Bradley KA, Boyko EJ: Brief questions to identify patients with inadequate health literacy. Fam Med 2004, 36(8):588-594.

86. Saelens BE, Sallis JF, Black JB, Chen D: Neighborhood-based differences in physical activity: an environment scale evaluation. Am J Public Health 2003 , 93(9):1552-1558.

87. Nord M, Coleman-Jensen A, Andrews M, Carlson S: Household food security in the United States, 2009: Darby, PA: DIANE Publishing; 2010

88. Bickel G, Nord M, Price C, Hamilton W, Cook J: Guide to Measuring Household Food Security. Alexandria, VA: Rev; 2000.

89. Carlson SJ, Andrews MS, Bickel GW: J Nutr 1999, 129(2S Suppl):510S-516S.

90. Sellers RM, Rowley SA, Chavous TM, Shelton JN, Smith MA: Multidimensional inventory of Black Identity: Preliminary investigation of reliability and construct validity. J Personal Soc Psychol 1997, 73(4):805-815.
91. Kessler RC, Barber C, Beck A, Berglund P, Cleary PD, McKenas D, Pronk N, Simon G, Stang P, Ustun TB, Wang P: The World Health Organization Health and Work Performance Questionnaire (HPQ). J Occup Environ Med 2003, 45(2):156-174

92. Kessler RC, Ames M, Hymel PA, Loeppke R, McKenas DK, Richling DE, Stang $P E$, Ustun TB: Using the World Health Organization Health and Work Performance Questionnaire (HPQ) to evaluate the indirect workplace costs of illness. J Occup Environ Med 2004, 46(6 Suppl):S23-S37.

93. Glasgow RE, Klesges LM, Dzewaltowski DA, Estabrooks PA, Vogt TM: Evaluating the impact of health promotion programs: using the RE-AIM framework to form summary measures for decision making involving complex issues. Health Educ Res 2006, 21(5):688.

94. Glasgow RE, McKay HG, Piette JD, Reynolds KD: The RE-AIM framework for evaluating interventions: what can it tell us about approaches to chronic illness management? Patient Educ Couns 2001, 44(2):119-127.

95. Glasgow RE, Vogt TM, Boles SM: Evaluating the public health impact of health promotion interventions: the RE-AIM framework. Am J Public Health 1999, 89(9):1322-1327.

96. Hill JO, Wyatt HR, Reed GW, Peters JC: Obesity and the environment: where do we go from here? Science 2003, 299(5608):853-855.

doi:10.1186/1471-2458-12-305

Cite this article as: Foley et al:: Weight gain prevention among black women in the rural community health center setting: The Shape Program. BMC Public Health 2012 12:305.

\section{Submit your next manuscript to BioMed Central and take full advantage of:}

- Convenient online submission

- Thorough peer review

- No space constraints or color figure charges

- Immediate publication on acceptance

- Inclusion in PubMed, CAS, Scopus and Google Scholar

- Research which is freely available for redistribution

Submit your manuscript at www.biomedcentral.com/submit 